\title{
Sexual behaviours and associated factors among students at Bahir Dar University: a cross sectional study
}

Wondemagegn Mulu*, Mulat Yimer ${ }^{\dagger}$ and Bayeh Abera ${ }^{\dagger}$

\begin{abstract}
Background: Sexual behaviour is the core of sexuality matters in adolescents and youths. Their modest or dynamic behaviour vulnerable them to risky sexual behaviours. In Ethiopia, there is scarcity of multicentered representative data on sexual behaviours in students to have a national picture at higher education. This study therefore conducted to assess sexual behaviours and associated factors at Bahir Dar University, Ethiopia.
\end{abstract}

Methods: A cross sectional study was conducted among Bahir Dar University students from December to February 2013. Multistage sampling and self administered questionnaires were employed. Descriptive statistics such as frequency and mean were used to describe the study participants in relation to relevant variables. Multivariate analysis was carried for those variables that had a p-value of $\leq 0.2$ in the bivariate analysis to identify the predictor variables.

Results: Of the 817 study participants, 297 (36.4\%) students had ever had sex. The mean age at first sexual practice was 18.6 years. Unprotected sex, having multiple sex partners, sex with commercial sex workers and sex for the exchange of money was practiced by $184(62 \%), 126(42.7 \%), 22(7.4 \%)$ and 12 (4\%) of sexually active students, respectively. The proportion of attending night clubs and watching porn videos was 130 (15.8\%) and 534 (65.4\%), respectively. Male respondents had significant positive association with watching porn videos ( $\mathrm{AOR}=4.8, \mathrm{Cl}=3.49-6.54$ ) and attending night clubs ( $\mathrm{AOR}=3.9, \mathrm{Cl}=2.3-6.7$ ). Watching porn videos, attending night clubs, khat chewing and taking alcohol frequently were significantly associated for ever had sex and having multiple sexual partners. Khat chewing practice $(A O R=8.5, C l=1.31-55.5)$ and attending night clubs ( $A O R=4.6, C l=1.8-11.77)$ had statistical significant association with the purpose of sexual intercourse for the sake of money and for having sex with commercial sex workers, respectively.

Conclusions: Significant number of students had different risky sexual behaviours. Substance use, attending night clubs and watching porno video were predictor factors for practicing different sexual behaviours. Therefore, preventive intervention programmes should be strengthened, effectively implemented and monitored both in the earlier school and in the universities.

Keywords: Sexual behaviours, University students, Associated factors, Bahir Dar

\footnotetext{
*Correspondence: Wondem_32@yahoo.com

${ }^{\dagger}$ Equal contributors

Bahir Dar University, College of Medicine and Health Sciences, Department

of Medical Microbiology, Immunology and Parasitology, Bahir Dar, Ethiopia
} 


\section{Introduction}

In adolescents and young people risky sexual behaviour has been recognized as an important health, social and demographic concern in the developing world [1]. Adolescent and youth are vulnerable to many health problems. Because they often have multiple sexual relationships and inconsistent use of condoms [2]. Young men may have their first sexual experiences with prostitutes, while young females may have their first sexual experiences with older men, both of which increase the chance of getting sexually transmitted infections (STIs) including Human Immunodeficiency Virus (HIV) [1,2]. Substance abuse exposes the users to risky sexual behaviours such as having unprotected sex which can have economic, social, physical, psychological, and health problems $[2,3]$.

University students are in the youth age category and are exposed to risky sexual behaviours such as unprotected sexual intercourse leading to HIV, other STIs and unwanted pregnancies [4-6]. Female youths are prone to unwanted pregnancies that lead unsafe abortions, severe illness, infertility and death $[3,7]$.

Young people aged 10-24 years constitute around 1.8 billion and represent $27 \%$ of the world's population [7]. Studies noted that as they are in the youth age category, their modest or dynamic behaviour vulnerable them to risky sexual behaviours $[7,8]$. Sexually transmitted diseases like HIV/AIDS and other reproductive health (RH) problems are the greatest threats to the well-being of adolescents and youth $[7,9]$.

Globally, one-third of the 340 million new STIs cases occur per year in people under 25 years of age. Each year, more than one in every 20 adolescents contracts a curable STI. Studies reported that more than half of all new HIV infections occur in people between the ages of 15 and 24 years $[7,10]$.

In Ethiopia, young people (aged 15-24) represented one of the country's largest groups, comprising about $35 \%$ of the population [11]. To enhance the sexual and reproductive health and well-being of the young's population, Ethiopia had a national strategies and activities. Some of the strategies are delivery of all youth RHrelated interventions and policies by gender, age, marital status, and residence; addressing the immediate and long-term RH needs of young people; and strengthening multicultural partnerships to respond to young women's heightened vulnerability to sexual violence and nonconsensual sex $[7,12]$. Some of the activities are creating awareness of sexual health, providing youth friendly services, increasing human resource capacity, explore new opportunities and expand multtisectorial coordination $[7,12]$. However, most related interventions targets the general public as a result it do not directly respond to higher education institution students need and expectation, making actual coverage of behavioural and biomedical interventions extremely low [13]. Therefore, sexual behaviour among adolescents and the youth is still a major issue in Ethiopia [11].

Previous studies conducted in other universities of Ethiopia showed a $26.9 \%$ to $34.2 \%$ of students ever had sexual intercourse. Of them, $45.2 \%$ had more than one sexual partner and $59.4 \%$ had first sex at high school. Moreover, the mean age at first sexual practice was 17.9 year and $4.4 \%$ of participants had sex with commercial sex workers [4,14-16]. Inadditon, different scholars also reported that different factors are responsible for the sexual behaviours of adolescents. Among those, use of alcohol and chewing khat are the common factors [4,17-19].

Although Ethiopia is in a concerted effort to enhance the sexual behaviour of youths using different strategy, activities and policies at the national level, the epidemic still continues to grow steadily in the country especially in educational setting claiming the lives of the most productive segments of the Ethiopian society that can lead to high social and economic costs, both immediately and in the years ahead. Moreover, dynamicity of adolescent's behaviour; it is assumed that student's sexual behaviour varies interms of locality, civilization, urbanization and socio cultural context of the societies. Specifically, Bahir Dar University is located in areas where there is high flow of tourists, comfortable pensions and night clubs that will expose the students to be engaged in different sexual risk behaviours. However, with the above problems, there is paucity of multicentered data representing the sexual behaviours of students in higher level institution at national level and also among Bahir Dar University students.Therefore, the purpose of this study was to assess the sexual behaviours and associated factors among students of Bahir Dar University, Ethiopia.

\section{Methods}

\section{Study design, period and area}

A cross-sectional study was conducted among students in Bahir Dar University (BDU) from December to February 2013. BDU is a public higher educational institution established in 2000 [20]. The University is located in Bahir Dar town 567 kilometres Northwest of Addis Ababa. It offers a wide range of higher education programs both at undergraduate and graduate levels [20]. BDU is now among the largest Universities in the Federal Democratic Republic of Ethiopia, with more than 35,000 students in its 57 undergraduate and 39 graduate programmes. At the time of the study, it has four campuses (Main campus, Poly campus, Zenzelma and Yibab campus) in Bahir Dar which had about 20,000 full time undergraduate students [20]. BDU has five student clinics. They are engaged in youth friendly services. At the time of data collection, information and counselling on sexual and reproductive health issues, 
promotion of healthy sexual behaviours through various methods including peer education, family planning information, counselling and method including emergency contraceptive methods and condom promotion and provision and abortion linkage service provided in youth friendly service. Currently each clinic has three nurses trained about youth friendly services [20,21].

\section{Study population}

All full time undergraduate students attending at Bahir Dar University during the study period.

\section{Inclusion criteria}

Full time undergraduate students ranging from year I to year $\mathrm{V}$ were included in the study.

\section{Exclusion criteria}

Post-graduate, extension, summer, advance standing and distance learning students were excluded during data collection.

\section{Sample size and sampling technique Sample size determination}

The sample size was determined using single population proportion formula considering the following assumptions: $\mathrm{P}=50 \%$ (The expected proportion of ever had sex among the students), 95\% confidence level and marginal error of $5 \%$.

The formula for calculating the sample size is:

$$
\begin{aligned}
\frac{(\mathrm{z} \alpha / 2) 2 \mathrm{p}(1-\mathrm{p})}{\mathrm{d}^{2}} & =(1.96)^{2}(0.5 \times 0.5) /(0.05)^{2} \\
& =384, \mathrm{n}=384
\end{aligned}
$$

Assuming 10\% non-response rate, design effect 2, the sample size was: $\mathrm{n}=384 \times 2+10 \%=768+76.7=848$. The final sample size was 848 . However, only 817 BDU students completed the questionnaire adequately.

\section{Sampling procedure}

Multistage sampling was used. To assure the representativeness of the data, the sample size was proportionally allocated to each college proportional to their number of students. Simple random sampling technique was used to select the departments from each year of study in the seven colleges. Finally the study participants were selected using systematic random sampling technique.

\section{Variables of the study}

\section{Dependent variable}

Sexual behaviours such as ever had sex, unprotected sex, having multiple sex partners, sex for the exchange of money and sex with commercial sex workers.

\section{Independent (explanatory) variables}

Socio-demographic variables such as age, sex, year of study, religion, ethncity, marital status and place of residence, alcoholism, khat chewing, attending night clubs and watching porn video.

\section{Operational definition \\ Unprotected sex}

Having sex without condom during their sexual experience.

\section{Protected sex}

Using condom during each and every sexual intercourse.

\section{Ever had sex}

Penile - vaginal sexual intercourse during each and every sexual intercourse.

\section{Data collection procedures}

A structured and self-administered questionnaire, which was partly adopted from Ethiopia Demographic and Health Survey (EDHS), Behavioural Surveillance Survey (BSS) and other relevant sources were used to collect the data [22,23]. All questionnaires were completed individually in the student clinic.

\section{Data quality control issues}

To maintain the quality of data, training was given to data collectors and supervisors on how to approach and select the study participants, on the objective of the study and the content of the questionnaire. Structured and self administered questionnaire was used. Questionnaire was pre-tested by taking 85 students from the university other than the actual study participant's. The questionnaire was first prepared in English and translated in to Amharic language for appropriateness and easiness. The Amharic version was again translated back to English to check for consistency of meaning.

\section{Data analysis}

The data was analysed using SPSS version 20. Descriptive statistics such as frequencies and mean were used to describe the study participants in relation to relevant variables. Most of the variables were fitted to the bivariate logistic regression. Then all variables having a $p$ value of $\leq 0.2$ in the bivariate analysis were further entered in to logistic regression model. In the multivariate analysis, backward step wise logistic regression techniques were fitted and confounding and multicolinearity were controlled. Variables having $\mathrm{p}$ value $<0.05$ in the multivariate analysis were taken as significant predictors. Crude and adjusted odds ratios with their 95\% confidence intervals were calculated. The Hosmer and Lemshow gardens-of-fit test was used to assess whether the 
necessary assumptions for the application of multiple logistic regression were fulfilled and $p$ - value $>0.05$ was considered a good fit.

\section{Ethical clearance}

Ethical clearance was obtained from Ethical review committee of Bahir Dar University, College of Medicine and Health Sciences. A formal approval was secured from Bahir Dar University and informed consent was obtained from the respondents before proceeding to the data collection. Confidentiality of the result was also maintained.

\section{Results}

\section{Socio-demographic characterstics}

A total of 817 full time undergraduate students with a response rate of $96.7 \%$ participated in the study. Of these, $545(66.7 \%)$ were males. The mean age of the respondents was 21 years ranged from 18 to 30 years. Majority 618 (75.6\%) of them were between 20-24 years. In ethncity, $466(57.1 \%)$ were from Amhara and 147 (18\%) were Oromo. Regards to religion, 624 (76.4\%) of the respondents were Orthodox Christian follower. In this study, $704(86.4 \%)$ were unmarried. Five hundred ten $(62.4 \%)$ of the study participants were either year one or two students. About, 802 (98.2\%) of the respondents live in the campus dormitory (Table 1).

\section{Sexual practice}

The overall proportion of ever had sexual practice was 297 (36.4\%). In the present study, ever had multiple sex partners was $126(42.7 \%)$ of the sexually active students. Having multiple sexual partners was 110 (48.5\%) and 16 (23.5\%) in males and females, respectively. Regards to condom use, $113(38 \%)$ of the sexually active respondents had consistently used condom during sex. Watching porn videos was noted in $534(65.4 \%)$ of respondents. The highest proportion $421(77.2 \%)$ was found in males (Table 1).

Sexual intercourse for the exchange of money was found in $12(4 \%)$ of the sexually active respondents (Table 2 ). The mean age at first sexual practice was 18.6 years. Seventy two $(24.3 \%)$ of the respondents initiated sexual activity before the age of 18 years. Moreover, among those respondents who ever had sex, $174(58.6 \%)$ had started sex during secondary school. However, 33 (11.1\%) had first sex during elementary school (Table 3).

Regarding the reason for ever had multiple sexual partners, seeking sexual pleasure and the effect of long term relationship was the major reason in males and females, respectively. On the other hand, among respondents who were not using condom consistently, 67 (36.4\%) reported that condom decreases sexual pleasure. Moreover, condom use reduces sexual pleasure was the leading reason among males while in love with a partner was the major reason among females for unprotected sex (Table 3). More importantly, need to wait until marriage, 363 (69.8\%) was the major reason for not initiating sexual intercourse and other reasons are listed in Table 3.

Ever had sex with commercial sex workers has been reported by $27(7.4 \%)$ of respondents. Sixty four (21.5\%) of sexually active students had an experience of sexual intercourse with older individuals. Engaging in sexual intercourse after watching porn videos, drinking alchol and chewing khat were noted in 73 (24.6\%), 102 (34.3\%) and $51(17.2 \%)$ of those students who ever had sexual intercourse respectively (Table 3 ).

\section{Multivariate analysis on sexual behaviours}

On multivariate analysis, age difference had significant association with ever had sex and watching porn videos. Those respondents with age of $20-24$ years $(\mathrm{AOR}=9.5$, $\mathrm{CI}=3.75-23.85)$ and $>24$ years $(\mathrm{AOR}=3.65, \mathrm{CI}=1.7-7.8)$ respectively were 10 and 3.6 times more likely to ever had sex. Those, respondents in the age group of $>24$ years were 3 times more likely to watch pornographic material than students with age group of $<20$ years $(\mathrm{AOR}=3.0$, $\mathrm{CI}=1.05$ - 8.39). Likewise, sex difference showed significant association with history of watching porn videos, attending night clubs and ever had sex for the exchange of money. Male respondents were 4.1 times to ever had watch porno videos compared to female respondents $(\mathrm{AOR}=4.1, \mathrm{CI}=2.88-5.75)$. However, female respondents were almost 3.7 times to practice sexual intercourse for the exchange money compared to male respondents $(\mathrm{AOR}=3.7, \mathrm{CI}=1.04-13.2)$ (Table 4). Furthermore, more males were night club attendants than females ( $\mathrm{AOR}=2.3, \mathrm{CI}=1.25$-3.43) (Table 5).

The proportion of ever had sex did not vary significantly by year of study and religion. Likewise, having multiple sexual partners did not vary significantly by sex, religion and ethncity (Table 4). Proportion of unprotected sex did not vary significantly by age, sex, residence, year of study, ethncity, religion and other explanatory variables.

Students who watched porn videos were 1.8 times more likely to had sex compared to non users $(\mathrm{AOR}=1.8, \mathrm{CI}=$ 1.19 - 2.59). Likewise, respondents who watched porn videos were 2.8 times more likely to had multiple sexual partners compared to those who did not watch porn videos $(\mathrm{AOR}=2.8, \mathrm{CI}=1.12-6.9)$. Night club attendants were 7 times more likely to had sexual practice (AOR $=7.4, \mathrm{CI}=4.23$-12.92) (Table 4). Similarly, attending night clubs was also the statistically significant associated factor for commencing sex with commercial sex workers $(\mathrm{AOR}=4.6, \mathrm{CI}=1.8-11.77)($ Table 5$)$.

Drinking alcohol regularly $(\mathrm{AOR}=1.9, \mathrm{CI}=1.35-2.83)$ was also an associated factor for ever had sexual intercourse. The proportion of having multiple sexual partners 
Table 1 Socio-demographic variables, ever had sex, multiple sex partners and unprotected sex among Bahir Dar University students, 2013

\begin{tabular}{|c|c|c|c|c|c|c|c|}
\hline \multirow[t]{2}{*}{ Variables } & \multicolumn{3}{|c|}{ Ever had sex $(\mathrm{N}=817)$} & \multicolumn{2}{|c|}{ Ever had multiple sex partners $(\mathrm{N}=297)$} & \multicolumn{2}{|c|}{ Unprotected sex $(\mathrm{N}=297)$} \\
\hline & $\begin{array}{c}\text { Yes } \\
\text { N (\%) }\end{array}$ & $\begin{array}{c}\text { No } \\
\text { N (\%) }\end{array}$ & $\begin{array}{l}\text { Total } \\
\text { N (\%) }\end{array}$ & $\begin{array}{c}\text { Yes } \\
\mathbf{N}(\%)\end{array}$ & $\begin{array}{c}\text { No } \\
\text { N (\%) }\end{array}$ & $\begin{array}{c}\text { Yes } \\
N(\%)\end{array}$ & $\begin{array}{c}\text { No } \\
\text { N (\%) }\end{array}$ \\
\hline \multicolumn{8}{|l|}{ Sex } \\
\hline Male & $229(42)$ & $316(58)$ & $545(66.7)$ & $110(48.5)$ & $16(23.5)$ & $138(60.3)$ & $91(39.7)$ \\
\hline Female & $68(25)$ & $204(78)$ & $372(33.3)$ & $117(51.5)$ & $52(76.5)$ & $46(67.6)$ & $22(32.4)$ \\
\hline \multicolumn{8}{|l|}{ Age } \\
\hline $18-20$ & $35(21)$. & $131(79)$ & $166(20.3)$ & $16(45.7)$ & $19(54.3)$ & $22(62.9)$ & $13(37.1)$ \\
\hline 20-24 & $239(38.7)$ & $379(61.3)$ & $618(75.6)$ & $98(41.2)$ & $140(58.8)$ & $145(60.7)$ & $94(39.3)$ \\
\hline$>24$ & $23(70)$ & $10(30)$ & $33(4)$ & $12(54.5)$ & $10(45.5)$ & $17(51.5)$ & $6(48.5)$ \\
\hline \multicolumn{8}{|l|}{ Religion } \\
\hline Orthodox & $236(37.8)$ & $388(62.2)$ & $624(76.4)$ & $92(39.3)$ & $142(60.7)$ & $145(61.7)$ & $90(38.3)$ \\
\hline Muslim & $22(26.8)$ & $60(73.2)$ & $82(10)$ & $8(36.4)$ & 14 (63.6) & $14(60.9)$ & $9(39.1)$ \\
\hline Protestant & $29(32.2)$ & $61(67.8)$ & $90(11)$ & $18(14.3)$ & $3(1.8)$ & $21(72.4)$ & $8(27.6)$ \\
\hline Other & $10(47.6)$ & $11(52.4)$ & $21(2.6)$ & $8(40)$ & $12(60)$ & $4(40)$ & $6(60)$ \\
\hline \multicolumn{8}{|l|}{ Year of study } \\
\hline Year one & $63(24.8)$ & $191(75.2)$ & $254(31.1)$ & $23(37.1)$ & $39(62.9)$ & $40(64.5)$ & $22(35.5)$ \\
\hline Year two & $98(38.3)$ & $158(61.7)$ & $256(31.3)$ & $43(43.4)$ & $56(56.6)$ & 65 (61.9) & $35(38.1)$ \\
\hline Year three & $98(49.7)$ & $99(50.3)$ & $197(24.1)$ & $44(45.8)$ & $52(54.2)$ & $57(59.4)$ & 39 (40.6) \\
\hline Year four & $24(36.9)$ & $41(63.1)$ & $65(8)$ & $9(37.5)$ & $15(62.5)$ & $16(66.7)$ & $8(33.3)$ \\
\hline Year five & $14(31.1)$ & $31(68.9)$ & $45(5.5)$ & $7(50)$ & $7(50)$ & $6(40)$ & $9(60)$ \\
\hline \multicolumn{8}{|c|}{ Place of residence } \\
\hline In the University & $291(36.3)$ & $511(63.7)$ & $802(98.2)$ & $524(65.3)$ & $122(96.8)$ & $180(62.1)$ & $110(37.9)$ \\
\hline Out of campus & $6(40)$ & $9(60)$ & $15(1.8)$ & $10(66.7)$ & $167(98.8)$ & $4(57.1)$ & $3(42.9)$ \\
\hline \multicolumn{8}{|l|}{ Marital status } \\
\hline Single & $241(34.2)$ & $463(65.8)$ & $704(86.2)$ & $109(45.6)$ & $130(54.4)$ & $141(58.8)$ & $99(41.3)$ \\
\hline Married & $47(46.5)$ & $54(53.5)$ & $101(12.4)$ & 15 (31.9) & 32 (68.1) & $36(75)$ & $12(25)$ \\
\hline Divorced & $5(71.4)$ & $2(28.6)$ & $7(0.9)$ & $1(20)$ & $4(80)$ & $5(100)$ & $0(100)$ \\
\hline Other & $4(80)$ & $1(20)$ & $5(0.6)$ & $1(25)$ & $3(75)$ & $2(50)$ & $2(50)$ \\
\hline \multicolumn{8}{|l|}{ Ethncity } \\
\hline Amhara & 153 (32.8) & $313(67.2)$ & $466(57.1)$ & $52(34.2)$ & $100(65.8)$ & $104(67.5)$ & $50(32.5)$ \\
\hline Oromo & $60(40.8)$ & 87 (59.2) & 147 (18) & 35 (59.3) & $24(40.7)$ & $31(52.5)$ & $28(47.5)$ \\
\hline Tigray & $38(45.8)$ & $45(54.2)$ & $83(10.2)$ & $18(47.4)$ & $20(52.6)$ & $21(55.3)$ & $17(44.7)$ \\
\hline Others & $46(38.3)$ & 74 (61.7) & $120(14.7)$ & $21(45.7)$ & $25(54.3)$ & $28(60.9)$ & 18 (39.1) \\
\hline Total & $297(36.4)$ & $520(63.6)$ & $817(100)$ & $127(42.8)$ & $170(57.2)$ & $184(70)$ & $113(30)$ \\
\hline
\end{tabular}

were more among sometimes alcohol drunkers than non drunkers $(\mathrm{AOR}=2.8, \mathrm{CI}=1.4-5.6)$ (Table 4). For attending night clubs, drinking alcohol irregularly $(\mathrm{AOR}=9.5$, $\mathrm{CI}=5.2-17.5)$ and regularly $(\mathrm{AOR}=3.3, \mathrm{CI}=1.1-10.1)$ were also statistically significant (Table 5 ).

Had multiple sexual partners was also 2.8 times more likely among khat chewers compared to non chewers $(\mathrm{AOR}=2.8, \mathrm{CI}=1.4-5.69)$. Chewing khat practice also significantly associated factor in engaging sexual intercourse for money $(\mathrm{AOR}=8.5, \mathrm{CI}=1.31-55.5)$ (Table 4).
Furthermore, chewing khat regularly $(\mathrm{AOR}=1.98, \mathrm{CI}=$ 1.08 - 3.64) and drinking alcohol $(\mathrm{AOR}=4.78, \mathrm{CI}=3.17$ 7.20) were statistically significant associated factors for watching porn videos (Table 5).

\section{Discussion}

In this study $36.4 \%$ of the students ever had sexual intercourse. This result is comparable to a study conducted in Nigeria (34\%) [24]. However, this proportion was higher than findings of BSS-II (9.9\%) [23], studies of 
Table 2 Socio-demographic variables, watching porn videos, attending night clubs and sex for the exchange of money among Bahir Dar University students, 2013

\begin{tabular}{|c|c|c|c|c|c|c|}
\hline \multirow[t]{2}{*}{ Variables } & \multicolumn{2}{|c|}{ Watching porn video $(\mathrm{N}=817)$} & \multicolumn{2}{|c|}{ Sex for the exchange of Money $(N=297)$} & \multicolumn{2}{|c|}{ Attending night clubs $(\mathrm{N}=817)$} \\
\hline & $\begin{array}{c}\text { Yes } \\
\text { N (\%) }\end{array}$ & $\begin{array}{c}\text { No } \\
\text { N (\%) }\end{array}$ & $\begin{array}{c}\text { Yes } \\
\text { N (\%) }\end{array}$ & $\begin{array}{c}\text { No } \\
\text { N (\%) }\end{array}$ & $\begin{array}{c}\text { Yes } \\
\text { N (\%) }\end{array}$ & $\begin{array}{c}\text { No } \\
\text { N (\%) }\end{array}$ \\
\hline \multicolumn{7}{|l|}{ Sex } \\
\hline Male & $421(77.2)$ & $124(22.8)$ & $7(3.1)$ & $221(96.6)$ & $112(20.6)$ & $433(79.4)$ \\
\hline Female & $113(41.5)$ & $159(76.5)$ & $5(7.2)$ & $64(92.8)$ & $18(6.6)$ & $254(93.4)$ \\
\hline \multicolumn{7}{|l|}{ Age } \\
\hline $18-20$ & $93(56)$ & $73(44)$ & $1(2.9)$ & $34(97.1)$ & $23(13.9)$ & $143(86.1)$ \\
\hline 20-24 & $414(67)$ & $204(33)$ & $10(4.2)$ & $229(95.8)$ & $99(16)$ & $519(84)$ \\
\hline$>24$ & $27(81.8)$ & $6(18.2)$ & $1(4.3)$ & $22(95.7)$ & $8(24.2)$ & $25(75.8)$ \\
\hline \multicolumn{7}{|l|}{ Religion } \\
\hline Orthodox & $413(66.2)$ & $211(33.8)$ & $8(3.4)$ & $227(96.6)$ & $103(16.5)$ & $521(83.5)$ \\
\hline Muslim & $48(55.8)$ & $38(44.2)$ & $1(4.3)$ & $21(95.7)$ & $9(11)$ & $73(89)$ \\
\hline Protestant & $6(75)$ & $2(25)$ & $0(0)$ & $27(93.1)$ & $10(11.1)$ & $80(88.9)$ \\
\hline Other & $67(65)$ & $36(35)$ & $1(9.1)$ & $10(90.9)$ & $8(38.1)$ & $13(61.9)$ \\
\hline \multicolumn{7}{|l|}{ Year of study } \\
\hline Year one & $147(57.9)$ & $107(42.1)$ & $4(6.3)$ & $59(93.7)$ & $26(10.2)$ & $228(89.8)$ \\
\hline Year two & $171(66.8)$ & $85(33.2)$ & $4(3.9)$ & $96(96.1)$ & $45(17.6)$ & $211(82.4)$ \\
\hline Year three & $147(74.6)$ & $50(25.4)$ & $4(4.1)$ & $92(95.5)$ & $46(23.4)$ & $151(76.6)$ \\
\hline Year four & $42(64.6)$ & $23(35.4)$ & $0(0)$ & $24(100)$ & $9(13.8)$ & $56(86.2)$ \\
\hline Year five & $27(60)$ & $18(40)$ & $0(0)$ & $14(100)$ & $4(8.9)$ & $41(91.1)$ \\
\hline \multicolumn{7}{|c|}{ Place of residence } \\
\hline In the university & $524(65.3)$ & $278(34.7)$ & $11(3.8)$ & $280(96.2)$ & $127(15.8)$ & $675(84.2)$ \\
\hline Out of campus & $10(66.7)$ & $5(33.3)$ & $1(16.7)$ & $5(83.3)$ & $3(20)$ & $12(80)$ \\
\hline \multicolumn{7}{|l|}{ Marital status } \\
\hline Single & $458(65.1)$ & $246(34.9)$ & $11(4.6)$ & $230(95.4)$ & $17(16.8)$ & $84(83.2)$ \\
\hline Married & $69(68.3)$ & $32(31.7)$ & $1(2.1)$ & $46(97.9)$ & $110(15.6)$ & $594(84.4)$ \\
\hline Divorced & $3(42.9)$ & $4(57.1)$ & $0(0)$ & $5(100)$ & $1(14.3)$ & $6(85.7)$ \\
\hline Other & $4(80)$ & $1(20)$ & $0(0)$ & $4(100)$ & $1(40)$ & $3(60)$ \\
\hline \multicolumn{7}{|l|}{ Ethncity } \\
\hline Amhara & $288(61.8)$ & $178(38.2)$ & $6(3.9)$ & $147(96.1)$ & $62(13.3)$ & 404 (86.7) \\
\hline Oromo & $106(72.1)$ & $41(27.9)$ & $3(5)$ & $57(95)$ & $28(19)$ & $119(81)$ \\
\hline Tigray & 57 (68.7) & $26(31.3)$ & $2(5.3)$ & $36(94.7)$ & $22(26.5)$ & $61(73.5)$ \\
\hline Others & $83(69.2)$ & 37 (30.8) & $1(2.2)$ & 45 (97.8) & $17(14.2)$ & $103(85.8)$ \\
\hline Total & $534(65.4)$ & $283(34.6)$ & $12(4.0)$ & $285(96)$ & $130(15.9)$ & $687(84.1)$ \\
\hline
\end{tabular}

other universities (26.9\% to $34.2 \%)$, Ethiopia [4,14-16] and a study conducted in Indian university (5\% for female and $15 \%$ for male students) [25]. In contrast, it is the lowest compared to other studies in Africa. For instance, 49\% to $59 \%$ of ever had sex in College and University students was reported in South Africa [26] and Uganda [27]. The possible explanation for the disparity in the proportion of sexual intercourse among adolescents of different studies could be due to different in traditional cultural back ground, sociodemographic characterstics, as well as difference in knowledge, attitude and practice towards HIV/AIDS.

Age at first sexual practice is an important indicator of exposure to the risk of unwanted pregnancy and STIs. The mean age at first sexual practice (18.6 years) for both males and females in this study is comparable to the reports of EDHS (18.2 years) [22], other universities in Ethiopia [14-16] and students of Madagascar (18.4 years) [26]. In contrast, the mean age of first sex was a bit higher than findings of Jimma University (17.7 years) [4] and 
Table 3 Other sexual and related behaviours of students at Bahir Dar University in relation to male and female, 2013

\begin{tabular}{l} 
Variables \\
\hline Age at first sex ( $\mathbf{N}=\mathbf{2 9 7})$ \\
$10-17$ \\
$18-19$ \\
$>20$ \\
Starting time of sexual intercourse $(\mathbf{N}=\mathbf{2 9 7})$ \\
Elementary school \\
High/preparatory school \\
In university \\
Other
\end{tabular}

Male
$\mathrm{N}(\%)$

Reason for having multiple sexual partners $(\mathrm{N}=297)$

To get partner with good sexual pleasure

Beautiful/handsome of partner

To get matured sexual partner

Effect of long term relation ship

Seeking for money

Other

Had sex with older individuals $(\mathrm{N}=297)$

Yes

No

Sex after watching porn videos $(\mathrm{N}=\mathbf{2 9 7})$

Yes

No

Sex after drinking alcohol $(\mathrm{N}=297)$

Yes

No

Had sex with commercial sex workers $(\mathrm{N}=297)$

Yes

No

Frequency of condom use $(\mathrm{N}=297)$

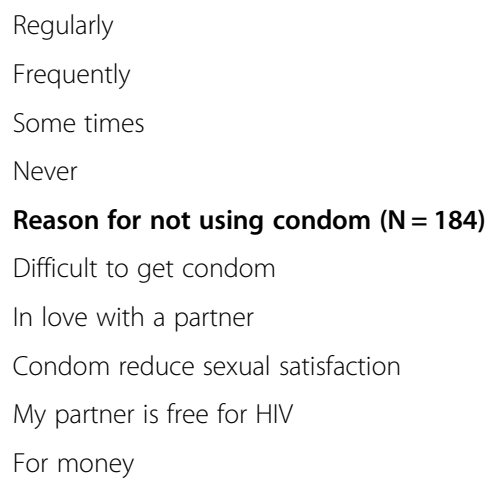

Reason for not using condom ( $\mathrm{N}=184)$

Difficult to get condom

In love with a partner

Condom reduce sexual satisfaction

My partner is free for HIV

For money

Reason for not practising sex until study period $(\mathrm{N}=520)$

Fear of HIV/other STIS

Fear of family

Need to wait until marriage
56 (24.7)

$106(46.7)$

65 (28.6)

24 (10.5)

$142(62.3)$

58 (25.4)

4 (1.8)

Female

N (\%)

Total

N (\%)

$16(23.2)$

$72(24.3)$

30 (43.5)

$136(45.9)$

$23(33.3)$

$89(29.7)$

9 (13)

33 (11.1)

32 (46.4)

174 (58.6)

25 (36.2)

83 (27.9)

$3(4.3)$

7 (2.4)

40 (35.4)

$1(7.7)$

41 (32.6)

21 (18.6)

9 (8)

27 (24)

$2(7.7)$

$22(17.5)$

3 (23.1)

$12(9.5)$

29 (23)

6 (4.8)

16 (12.7)

$11(9.7)$

1 (7.7)

5 (35.7)

64 (21.5)

52 (22.7)

12 (17.6)

$233(78.5)$

$177(77.3)$

$56(82.4)$

73 (24.6)

$64(27.9)$

$9(13.2)$

$224(75.4)$

165 (72.1)

59 (86.8)

102 (34.3)

88 (38.4)

14 (20.6)

195 (65.7)

141 (61.6)

54 (79.4)

$22(7.4)$

22 (9.6)

$0(0)$

68 (100)

275 (92.6)

91 (39.7)

22 (32.4)

$113(38)$

71 (31)

$11(16.2)$

82 (27.6)

15 (6.6)

52 (22.7)

$10(4.4)$

25 (8.4)

25 (10.9)

77 (25.9)

19 (13.7)

2 (4.4)

21 (11.4)

27 (19.4)

16 (35.6)

43 (23.4)

56 (40.3)

11 (24.4)

67 (36.4)

36 (25.9)

13 (28.9)

49 (26.6)

$1(0.7)$

$3(6.7)$

$4(2.2)$

46 (14.6)

$10(4.9)$

56 (10.8)

7 (2.2)

$1(0.5)$

8 (1.5)

$192(60.8)$ 
Table 3 Other sexual and related behaviours of students at Bahir Dar University in relation to male and female, 2013 (Continued)

\begin{tabular}{lll}
\hline To prevent unwanted pregnancy & $5(1.6)$ & $9(4.4)$ \\
Need to wait until marriage + Fear of HIV & $52(16.5)$ & $9(4.4)$ \\
Has no specific reason & $14(4.4)$ & $4(2)$
\end{tabular}

Gomo Gofa (17 years) [28]. Moreover, more than half (58.6\%) of sexually active students had first sex during secondary school. This conforms with studies of other Universities in Ethiopia ranged from $58.5 \%$ to $75.2 \%$ [4,14-16]. This might indicate that early sexual imitation problem is the issue not only at university level, but also at high school and elementary level. Therefore, secondary school students should be targeted with preventive interventions as youth to discourage premature initiation of sexual activity. The result of multiple logistic regression model revealed an age related increased proportion of ever had penile vaginal sex where as age increased the proportion of sexual experience was increased. Respondents aged 20 years and older significantly more likely than those below 20 years to report that they had sexual experience. This is in line with reports from 2011 EDHS [22].

The proportion of ever had multiple sexual partners among those who had sexual intercourse was $42.7 \%$. Similar comparable finding was noted in Bahir Dar city at private college students [29] and in Gonder [30]. However, high rate of multiple sex partners was reported in Wolaita University [31]. In contrast, a study in Haramaya [15] and Jimma University [4] reported lower rate of ever had multiple sexual partners. The difference could be due to difference in sample size, study population and comprehensive university based behavioural change interventions.

Engaging in risk behaviours such as Khat chewing, drinking alcohol, attending night clubs and watching porno videos were independently associated with likely hood of ever had sex and having multiple sexual partners. It is in line with study from Slovakia [32] and other universities in Ethiopia [4,14-16]. This could be due to risk perception ability decreases with alcohol and khat consumption as a result students may not be capable of rational judgment and they also may not be able to predict the serious consequence of their action.

The frequency of unprotected sexual practice in this study (62\%) was comparable with study done in Jimma University (57.6\%) [4] and higher education of Cambodia [33]. However, it was higher than study from Medawolabu University (40.4\%), Ethiopia [34]. Moreover, the level of consistently use of condom (38\%) among sexually active students was lower than other studies, Ethiopia $[15,29,34]$ that documented $48 \%-81 \%$ of consistently condom use. This may be because of dynamicity of adolescent's behaviour, difference in knowledge on risky sexual behaviours, reproductive health issues and skills of condom use.

According to this study, $7.4 \%$ of the sexually active students had sexual intercourse with commercial sex workers. This is lower than findings of other Universities in Ethiopia $[4,31,34]$ where the rate of sex with commercial sex workers was $13.9 \%$ to $24.9 \%$. This difference might be difference in awareness about mode of transmission and risk sexual behaviours among students in different Universities. Although attending night clubs was the only risk factor for engaging in sexual intercourse with commercial sex workers, Bahir Dar University has been started regulation mechanism that might limits the students from attending night clubs. The rules prevent students not to stay out of the campus during the night time.

In this study, the occurrence of exchanging sex for the sake of money was $4 \%$. It is comparable with the cumulative proportion of other Universities of Ethiopia (4.4\%) $[4,14,15]$. In contrast, it is lower than other study in Bahir Dar city [35] private college students and Addis Ababa where exchange sex among adolescents was $20.6 \%$ [36] and among university students was $14.5 \%$ [37]. Exchanging sex for money was significantly practiced in female than males.

In many societies young women have sexual relationship with men who are considerably older than them. This practice can contribute to the spread of HIV and other STIs because older men are more likely to have been exposed for those diseases. In this study, $21.5 \%$ of sexually active respondents had sex with older individuals. Similarly, according to EDHS study, over all $21 \%$ of women age 15-19 who had sexual intercourse had sex practice with a man ten or more years older than them and very few young men, $<1 \%$ had sex with older women [22].

The proportion of watching porn videos in this study $(65.4 \%)$ is comparable with other finding in Ethiopia (47.2\%) [30]. However, our finding was significantly higher than studies done at Medawolabu (15.6\%) [34] and Jimma Universities (32.4\%) [4]. The highest proportion of watching porn videos detected among males and those whose age $>24$ years old respondents. This might be associated with existence of sub cultural difference.

In this study, the proportion of attending night clubs is comparable with study in Bahir Dar city private college [29] and Jimma university students [4]. Male respondents were 2.2 times to attend night clubs than females. This 
Table 4 Bivariate and multivariate analysis of factors associated with ever had sex, having multiple sex partners, and sex for the exchange of money among students of Bahir Dar University, 2013

\begin{tabular}{|c|c|c|c|c|c|c|c|}
\hline \multirow[t]{2}{*}{ Variables } & & \multicolumn{2}{|c|}{ Ever had sex } & \multicolumn{2}{|c|}{ Having multiple sexual partners } & \multicolumn{2}{|c|}{ Sex for the exchange of mone } \\
\hline & & $\begin{array}{c}\text { COR } \\
(95 \% \mathrm{Cl})\end{array}$ & $\begin{array}{c}\text { AOR } \\
(95 \% \mathrm{Cl})\end{array}$ & $\begin{array}{c}\text { COR } \\
(95 \% \mathrm{Cl})\end{array}$ & $\begin{array}{c}\text { AOR } \\
(95 \% \mathrm{Cl})\end{array}$ & $\begin{array}{c}\text { COR } \\
(95 \% \mathrm{Cl})\end{array}$ & $\begin{array}{c}\text { AOR } \\
(95 \% \mathrm{Cl})\end{array}$ \\
\hline \multicolumn{8}{|l|}{ Sex } \\
\hline & Male & $2.2(1.6-3.0)^{* *}$ & $0.9(0.6-1.3)$ & $3.1(1.7-5.7)^{* *}$ & $1.4(0.7-3.0)$ & $2.4(0.8-7.9)$ & $3.7(1.1-13.2)^{* *}$ \\
\hline & female & 1 & 1 & 1 & 1 & 1 & 1 \\
\hline \multicolumn{8}{|l|}{ Age } \\
\hline & $18-20$ & 1 & 1 & & 1 & & \\
\hline & $21-24$ & $8.6(3.75-19.78)^{* *}$ & $9.5(3.8-23.9)^{* *}$ & - & - & - & - \\
\hline & $>24$ & $3.65(1.7-7.8)^{* *}$ & $3.6(1.6-8.3)^{* *}$ & - & - & - & - \\
\hline \multicolumn{8}{|c|}{ Year of study } \\
\hline & Year I & 1 & 1 & & - & - & - \\
\hline & Year II & $0.53(0.4-0.8)^{* *}$ & $0.8(0.5-1.3)$ & - & - & - & - \\
\hline & Year III & $0.3(0.2-0.5)^{* *}$ & $0.6(0.4-1.0)$ & - & - & - & - \\
\hline & Year IV & $0.6(0.3-1.0)$ & $0.9(0.5-1.8)$ & - & - & - & - \\
\hline & Year V & $0.7(0.4-1.5)$ & $1.1(0.5-2.4)$ & - & - & - & - \\
\hline \multicolumn{8}{|l|}{ Ethncity } \\
\hline & Amhara & - & - & $0.6(0.3-1.2)$ & $0.9(0.4-2.2)$ & - & - \\
\hline & Oromo & - & - & $1.7(0.8-3.8)$ & $1.6(0.6-4.3)$ & - & - \\
\hline & Tigray & - & - & $1.1(0.5-2.5)$ & $1.3(0.5-3.9)$ & - & - \\
\hline & Other & - & - & 1 & 1 & - & - \\
\hline \multicolumn{8}{|l|}{ Religion } \\
\hline & Orthodox & $1.5(0.6-3.6)$ & $0.9(0.3-3.2)$ & $0.2(0.0-0.8)$ & $0.4(0.1-2.7)$ & - & - \\
\hline & Muslim & $2.5(0.9-6.6)$ & $1.7(0.5-6.1)$ & $0.1(0.2-0.8)$ & $0.3(0.0-2.5)$ & - & - \\
\hline & Protestant & $1.9(0.7-5.0)$ & $1.1(0.3-4.1)$ & $0.4(0.1-2.3)$ & $1.3(0.2-9.6)$ & - & - \\
\hline & Other & 1 & 1 & 1 & 1 & & \\
\hline \multicolumn{8}{|c|}{ Attending night clubs } \\
\hline & Yes & $12.9(7.9-21.1)^{* *}$ & $7.4(4.2-12.9)^{* *}$ & $6.8(3.9-11.5)^{* *}$ & $3.1(1.7-5.7)^{* *}$ & - & - \\
\hline & No & 1 & 1 & 1 & 1 & - & - \\
\hline \multicolumn{8}{|c|}{ Watching porn video } \\
\hline & Yes & $3.3(2.4-4.7)^{* *}$ & $1.8(1.2-2.6)^{* *}$ & $5.7(2.6-12.5)^{* *}$ & $2.8(1.1-6.9)^{* *}$ & - & - \\
\hline & No & 1 & 1 & 1 & 1 & - & - \\
\hline \multicolumn{8}{|l|}{ Alcoholism } \\
\hline & Never & 1 & 1 & 1 & 1 & 1 & 1 \\
\hline & Always & $4.3(3.1-5.8)^{* *}$ & $1.9(1.4-2.8)^{* *}$ & $9.47(2.6-34.7)^{* *}$ & $4.4(0.9-20.8)$ & $0.1(0.0-0.8)$ & $2.3(0.4-13.7)$ \\
\hline & Sometime & $2.4(1.1-4.1)^{* *}$ & $2.2(0.9-5.5)$ & $6.3(3.5-11.2)^{* *}$ & $2.8(1.4-5.6)^{* *}$ & $0.4(0.1-1.8)$ & $0.04(0.0-1.5)$ \\
\hline
\end{tabular}

Chewing khat

$$
\begin{array}{lcccccc}
\text { Never } & 1 & 1 & 1 & 1 & 1 & 1 \\
\text { Sometimes } & 12(4.1-35.6)^{* *} & 3.3(1.0-11.2)^{* *} & 5.2(2.9-9.0)^{* *} & 2.3(1.2-4.5)^{* *} & 0.3(0.1-0.9)^{* *} & 8.5(1.3-55.5)^{* *} \\
\text { Always } & 2.6(0.8-8.2) & 1.7(0.5-6.2) & 9.9(3.2-31.0)^{* *} & 2.8(1.4-5.7)^{* *} & 0.2(0.0-1.1) & 1.8(0.3-10.1) \\
\hline
\end{array}
$$

Key: COR: crude odds ratio, AOR: adjusted odds ratio, $\mathrm{Cl}$ : Confidence interval, --: those variables who had p-value $>0.2$ in bivariate analysis, ${ }^{1}$ : Reference category, **Significant association.

might be associated with males feel more freedom and comfort to attend night clubs than females because of local cultural influence. Ethnical difference was also significantly associated with attending night clubs (Table 5). This might be associated with sub cultural difference and influence of the values and norms of the local community. 
Table 5 Bivariate and Multivariate analysis of factors associated with watching porn video, attending night clubs and sex with commercial sex workers among students of Bahir Dar University, 2013

\begin{tabular}{|c|c|c|c|c|c|c|c|}
\hline \multicolumn{2}{|l|}{ Variables } & \multicolumn{2}{|c|}{ Watching porn videos } & \multicolumn{2}{|c|}{ Attending night clubs } & \multicolumn{2}{|c|}{ Sex with commercial sex workers } \\
\hline Sex & & \multirow{3}{*}{$\begin{array}{c}\text { COR } \\
(95 \% \mathrm{Cl}) \\
4.8(3.5-6.5)^{* *} \\
1\end{array}$} & \multirow{3}{*}{$\begin{array}{c}\text { AOR } \\
(95 \% \mathrm{Cl}) \\
4.1(2.9-5.8)^{* *} \\
1\end{array}$} & \multirow{3}{*}{$\begin{array}{c}\begin{array}{c}\text { COR } \\
(95 \% \mathrm{Cl})\end{array} \\
3.9(2.3-6.7)^{* *} \\
1\end{array}$} & \multirow{3}{*}{$\begin{array}{c}\text { AOR } \\
(95 \% \mathrm{Cl}) \\
2.3(1.3-4.3)^{* *} \\
1\end{array}$} & $\begin{array}{c}\text { COR } \\
(95 \% \mathrm{Cl}) \\
\end{array}$ & $\begin{array}{c}\text { AOR } \\
(95 \% \mathrm{Cl})\end{array}$ \\
\hline & Male & & & & & NA & NA \\
\hline & female & & & & & & \\
\hline \multicolumn{8}{|l|}{ Age } \\
\hline & $18-20$ & 1 & 1 & & & & \\
\hline & $20-24$ & $3.5(1.4-9.0)^{* *}$ & $1.3(0.9-2.0)$ & - & - & - & - \\
\hline & $>24$ & $2.2(0.9-5.5)$ & $3.0(1.1-8.4)^{* *}$ & - & - & - & - \\
\hline \multicolumn{8}{|c|}{ Year of study } \\
\hline & Year I & 1 & 1 & 1 & 1 & & \\
\hline & Year II & $0.7(0.5-0.9)$ & $1.2(0.8-1.8)$ & $1.2(0.4-3.5)$ & $2.3(0.6-9.2)$ & - & - \\
\hline & Year III & $0.5(0.3-0.7)$ & $1.6(0.9-2.6)$ & $2.2(0.8-6.4)$ & $3.4(0.9-13.5)$ & - & - \\
\hline & Year IV & $0.8(0.4-1.3)$ & $1.2(0.6-2.5)$ & $3.1(1.1-9.2)^{* *}$ & $3.7(0.9-14.4)$ & - & - \\
\hline & Year V & $0.9(0.5-1.8)$ & $1.3(0.6-2.8)$ & $1.7(0.5-5.7)$ & $2.8(0.6-13.5)$ & - & - \\
\hline \multicolumn{8}{|l|}{ Ethncity } \\
\hline & Amhara & $1.4(0.9-2.1)$ & $0.7(0.4-1.2)$ & $0.9(0.5-1.7)$ & $1.8(0.8-3.7)$ & - & - \\
\hline & Oromo & $0.9(0.5-1.5)$ & $1.3(0.7-2.4)$ & $1.4(0.7-2.8)$ & $1.95(0.8-4.5)$ & - & - \\
\hline & Tigray & $1.02(0.6-1.9)$ & $1.2(0.6-2.3)$ & $2.2(1.1-4.4)^{* *}$ & $5.6(2.2-14.2)^{* *}$ & - & - \\
\hline & Other & 1 & 1 & 1 & 1 & - & - \\
\hline \multicolumn{8}{|l|}{ Religion } \\
\hline & Orthodox & - & - & 1 & 1 & & \\
\hline & Muslim & - & - & $0.6(0.3-1.3)$ & $0.73(0.3-1.8)$ & - & - \\
\hline & Protestant & - & - & $0.6(0.3-1.3)$ & $0.73(0.3-1.9)$ & - & - \\
\hline & Other & - & - & $3.1(1.3-7.7)^{* *}$ & $4.0(1.0-16.1)$ & - & - \\
\hline \multicolumn{8}{|l|}{ Chewing } \\
\hline \multirow[t]{3}{*}{ khat } & Never & 1 & 1 & 1 & 1 & 1 & 1 \\
\hline & Some times & $4.1(2.4-6.9)^{* *}$ & $2.0(1.1-3.6)^{* *}$ & $9.8(6.3-15.4)^{* *}$ & $6.48(3.9-10.9)^{* *}$ & $0.3(0.1-0.9)^{* *}$ & $0.54(0.2-1.5)$ \\
\hline & Always & $1.1(0)$ & $1.1(0)$ & $27.2(10.8-68.3)$ & $18.7(6.4-53.9)^{* *}$ & $0.3(0.1-1.1)$ & $0.38(0.1-2.2)$ \\
\hline \multicolumn{8}{|l|}{ Alcoholism } \\
\hline & Never & 1 & 1 & 1 & 1 & 1 & 1 \\
\hline & Always & $1.2(0.6-2.4)$ & $0.61(0.3-1.4)$ & $9.3(3.6-24)^{* *}$ & $3.3(1.1-10.1)^{* *}$ & $0.3(0.0-3.3)$ & $0.8(0.1-9.9)$ \\
\hline & Sometimes & $6.4(4.4-9.4)^{* *}$ & $4.78(3.2-7.2)^{* *}$ & $15.8(8.9-27.7)^{* *}$ & $9.5(5.2-17.5)^{* *}$ & $0.2(0.1-0.9)^{* *}$ & $0.6(0.1-2.3)$ \\
\hline \multicolumn{8}{|l|}{ Attending } \\
\hline \multirow[t]{2}{*}{ night clubs } & Yes & $4.2(0.3-7.2)$ & $0.9(0.5-1.8)$ & NA & NA & $4.2(1.7-10.8)^{* *}$ & $4.6(1.8-1.8)^{* *}$ \\
\hline & No & 1 & 1 & & & 1 & 1 \\
\hline
\end{tabular}

Key: COR: Crude odds ratio, AOR: adjusted odds ratio, Cl: Confidence interval, -- , those variables who had $p$-value of $>0.2$ in the bivariate analysis, NA: Not applicable, ${ }^{1}$ : Reference category, ${ }^{* *}$ Significant association.

The major limitation of this study was the nature of cross sectional study which may not explain the temporal relationship between the outcome variable and some explanatory variables. The study topic by itself assesses personnel and sensitive issues related to sexuality which might have caused social desirability bias. Thus, the finding of this study should be interpreted with these limitations.

\section{Conclusions}

The study revealed a more comprehensive understanding of the sexual behaviours of Bahir Dar University 
students. Risky sexual behaviours such as early age sex, having multiple sexual partners, unprotected sex, and sex with commercial sex workers are significantly practiced among students in Bahir Dar University. Substance use, attending night clubs and watching porno video were predictor factors for the existence of different sexual behaviours. Therefore, preventive intervention programmes should be strengthened, effectively implemented and monitored both in the earlier school and at the university level.

\section{Competing interests}

The authors declare that they have no competing interests.

\section{Authors' contributions}

WM Conceived and designed the study, involved in data collection, performed statistical analysis, drafted and finalized the manuscript for publication. BA Conceived and designed the study, involved in data collection and analysis, critically revised the manuscript. MY Participated in reviewing the proposal, critically revised the manuscript. All authors read and approved the final manuscript.

\section{Authors' information}

WML Assistant professor at College of Medicine and Health Sciences, Bahir Dar University in Medical Microbiology. BAB Associate professor of Medical microbiology, department head of Microbiology, Immunology and Parasitology at College of Medicine and Health Sciences, Bahir Dar University. MYM Assistant professor at College of Medicine and Health Sciences, Bahir Dar University in Medical Parasitology.

\section{Acknowledgments}

Bahir Dar University is acknowledged for funding the project. We authors grateful to acknowledge, BDU HIV/AIDS prevention and controlling office for coordinating the data collection process. We would like also to thank Mr Lemma Kassaye, Bahir Dar University HIV/AIDS affairs director and Sister Martha Asmare, Bahir Dar University student's affair for their contribution in coordinating and facilitating the data collection process. We also like to pass our heartfelt thanks to students.

\section{Received: 27 October 2013 Accepted: 29 November 2014}

Published: 6 December 2014

\section{References}

1. Somba MJ, Mbonile M, Obure J, Mahande MJ: Sexual behaviour, contraceptive knowledge and use among female undergraduate students of Muhimbili and dares Salaam Universities, Tanzania: a cross sectional study. BMC Womens Health 2014, 14:94.

2. Ambaw F, Mossie A, Gobena T: Sexual practices and their development pattern among Jimma university students. Ethiop J Health Sci 2010, 20(1):159-167.

3. Ministry of Health: Federal democratic republic of Ethiopia: adolescent and youth reproductive health. In MOH; 2011:1-149.

4. Tura G, Alemseged F, Dejene S: Risky sexual behaviour and predisposing factors among students of Jimma University. Ethiop J Health Sci 2012, 22(3):170-180.

5. World Health Organization: Investing in our future: A framework for accelerating action for the sexual and reproductive health of the young people. Geneva: WHO; 2006.

6. Lanre OO: Sexual behaviour of university students in South west Nigeria. Egypt Acad J biolog Sci 2009, 1(1):85-93.

7. Shiferaw K, Frehiwot G, Asres G: Assessment of adolescents communication on sexual and reproductive health matters with parents and associated factors among secondary and preparatory schools' students in Debremarkos town, North west Ethiopia. Reprod Health 2014, 11:2.

8. Sime A, Writu D: Premarital sexual practice among school adolescents in Nekemte town east Wollega. Ethiop J Health Dev 2008, 22(2):167-173.
9. Berhane F, Berhane Y, Fantahun M: Adolescents health service utilization pattern and preferences: consultation for reproductive health problems and mental stress are less likely. EthiopJ Health Dev 2005, 19(1):29-36.

10. Fikre M: Assessment of parent-adolescent communication on sexual and reproductive health matters in Hawassa town; 2009:42.

11. United States Agency for International Development: Path finder international. Bringing youth friendly services to scale in Ethiopia. In USAID; 2012:1-8.

12. Ministry of Health: Federal Democratic Republic of Ethiopia. National reproductive health strategy 2006 - 2015. In MOH; 2006:24-27.

13. Lamesgin A: HIV/AIDS and sexual reproductive health among University students in Ethiopia: A policy intervention frame work. USAID 2013, 1-5.

14. Shiferaw Y, Alemu A, Assefa A, Tesfaye B, Gibremdehin E, Amare M: Perception of risk of HIV and sexual risk behaviours among University students: Implication for planning interventions. BMC Res Notes. 2014, 7:162.

15. Dingeta T, Oljira L, Alemayehu T, Akililu A: First sexual intercourse and risky sexual behaviors among undergraduate students at Haramaya University, Ethiopia. Ethiop J Reprod Health 2011, 5(1):22-30.

16. Berhan $Y$, Hailu D, Alano A: Predictors of sexual- risk behaviour and HIV- preventive practices among University students in Ethiopia. Afr J AIDS Res 2011, 10(3):225-234.

17. Lundberg P, Rukando G, Asheba S, Thorson A, Allebeck P, Ostergren P, Cantor-Grae E: Poor mental health and sexual risk behaviours in Uganda. BMC Public Health 2011, 11:2-10.

18. Gebreslassie M, Feleke A, Melese T: Psychoactive substances use and associated factors among Axum University students, Axum town, North Ethiopia. BMC Public Health 2013, 13:2-9.

19. Tilahun MM, Ayele GA: Factors associated with alcohol use among youths in Gamo Gofa, South west, Ethiopia. Sci J Public Health 2013, 1(2):62-68.

20. BahirDar University back ground information. Available at www.bdu.edu.et/ background on July 10, 2013.

21. Tewabe T, Destaw B, Admassu M, Abera B: Assessment of factors associated with voluntary counselling and testing uptake among students in Bahir Dar university a case control study. Ethiop J Health dev 2012, 26(1):17-21.

22. CSA and ORC Macro: Report of Ethiopia Demographic and Health Survey 2005. Addis Ababa, Ethiopia, and Calverton, Maryland, USA: Central Statistical Authority and ORC Macro; 2006.

23. Ministry of Health: Federal Republic of Ethiopia: HIV/AIDS Behavioral Surveillance Survey (BSS). In MOH; 2002:1-123.

24. Slap GB, Lot L, Huang B, Daniyam CA, Zink TM, Succop PA: Sexual behaviour of adolescents in Nigeria: cross sectional survey of secondary school students. BMJ 2003, 326:15.

25. Sujay R: Premarital sexual behaviour among unmarried College Students of Gujarat, India. Health and Population Innovation Fellowship Programm working paper. New Delhi Population counsel; 2009.

26. Rahamefy O, Rivard M, Ravaoarinoro M: Sexual behaviour and condom use among University students in Madagascar. JSoc aspects of HIV/AIDS 2008, 5:28-34.

27. Agardh A, Emmelin M, Muriisa R, Ostergren P: Social capital and sexual behaviour among Ugandan University students. Glob Health Action 2010, 3: 5432-doi:10.3402/gha.v3io.5432.

28. Tilahun $\mathrm{T}$, Ayele $\mathrm{G}$ : Factors associated with age at first sexual initiation among youths in Gamo Gofa, south west Ethiopia: a cross sectional study. BMC Public Health 2013, 13:2-6.

29. Anteneh ZA: Prevalence and correlates of multiple sexual partnerships among private college students in Bahir Dar city, Northwest Ethiopia. SciJ Public Health 2013, 1(1):9-17.

30. Shiferaw Y, Alemu A, Girma A, Getahun A, Kassa A, Gashaw A, Alemu A, Teklu T, Gelaw B: Assessment of knowledge, attitude and risk behaviours towards HIV/AIDS and other sexual transmitted infection among preparatory students of Gondar town, North west Ethiopia. BMC Res Notes 2011, 4:3-8.

31. Gelibo T, Belachew T, Tilahun T: Predictors of sexual abstinence among Wolaita Sodo University Students, South Ethiopia. Reprod Health 2013, 10:2-6.

32. Ondrej K, Andrea MG, Pavol J: Psychological and behavioural factors associated with sexual behaviour among Slovak students. BMC Public Health 2009, 9:15.

33. Siyan $Y$, Krishna CP, Junko Y: Role of risk and protective factors in risky sexual behaviour among high school students in Cambodia. BMC Public Health 2010, 10:477. 
34. Setegn TM, Takele AM, Dida NB, Tulu BE: Risks for SITs/HIV infection among Madawalabu University students, Southeast Ethiopia: A cross sectional study. Reprod Health 2013, 10:2-7.

35. Alamirew Z, Awoke W, Fikadie G, Shimekaw B: Prevalence and correlates of exchanging sex for money (gift) among private college students in BahirDar city, Northwest Ethiopia. Clin Medi Res 2013, 2(6):126-134.

36. Regassa N, Kedir S: Attitudes and practices on HIV preventions among students of higher education institutions in Ethiopia. The case of Addis Ababa University. Edu Res 2011, 2(2):828-840.

37. Amsale C, Yemane B: Peer pressure is the prime driver of Risky sexual behaviours among school adolescents in Addis Ababa, Ethiopia. World J AIDS 2012, 2:159-164.

doi:10.1186/1742-4755-11-84

Cite this article as: Mulu et al: Sexual behaviours and associated factors among students at Bahir Dar University: a cross sectional study.

Reproductive Health 2014 11:84

\section{Submit your next manuscript to BioMed Central and take full advantage of:}

- Convenient online submission

- Thorough peer review

- No space constraints or color figure charges

- Immediate publication on acceptance

- Inclusion in PubMed, CAS, Scopus and Google Scholar

- Research which is freely available for redistribution 